\title{
Application of non-contrasted computed tomography and diffusion-weighted imaging protocols for endovascular treatment selection in patients with late-presenting or wake-up strokes
}

\author{
Aplicação de tomografia computadorizada sem contraste e protocolos de imagem \\ ponderada em difusão para seleção de tratamento endovascular em pacientes com \\ acidente vascular cerebral em fase tardia ou ao despertar
}

Wei MING ${ }^{1,2,3}$, Wang SHUYUAN'1 , Ren HECHENG' ${ }^{1}$ Ma LIN'1 , Yin LONG ${ }^{1}$

\begin{abstract}
Background: Among patients with acute ischemic stroke with a mismatch between deficit severity and infarct volume, thrombectomy performed within a 6-24 hours time window has efficacy and safety similar to treatment within 6 hours. However, whether magnetic resonance imaging with T2 diffusion-weighted imaging (DWI) is feasible remains to be validated. Objective: To investigate prognosis among stroke patients receiving endovascular treatment (EVT) within 6 hours and 6-24 hours using non-contrasted computed tomography (NCCT) and DWI. Methods: Overall, 209 anterior-circulation ischemic stroke patients with large-vessel occlusion who underwent EVT were divided into $\leq 6$ hours and 6-24 hours groups. Patients presenting symptoms within 6 hours were treated if their NIHSS score was $\geq 7$ and ASPECTS score was $\geq 5$, whereas those with wake-up stroke (WUS) or presenting symptoms 6-24 hours after last seen well (WUS/late-presenting stroke, LPS) were managed if their NIHSS score was $\geq 7$ and ASPECTS score was $\geq 5$. Results: The percentages of patients undergoing intracranial stenting and intracranial ballooning without stenting significantly differed between two groups ( $p<0.001)$. Grades $0,1,2 a$ and $2 b$ recanalization rates did not differ between the 6 hours and 6-24 hours groups (all $p>0.05$ ). Grade 3 recanalization rate in the 6 hours group was significantly lower than in the 6-24 hours group ( $p=0.043$ ). The 3-month Rankin Scale score did not significantly differ between the two groups $(p=0.629)$. Conclusions: EVT is a safe and effective treatment for patients with WUS and LPS selected through NCCT and DWI-based simple imaging.

Keywords: Endovascular Treatment; Non-contrast Computed Tomography; Diffusion Magnetic Resonance Imaging; Stroke.
\end{abstract}

RESUMO

Antecedentes: Entre pacientes com acidente vascular cerebral isquêmico (AVCl) agudo com divergência entre gravidade do déficit e volume do infarto, a trombectomia em 6 a 24 horas tem eficácia e segurança semelhantes ao tratamento em até 6 horas. Entretanto, a viabilidade da imagem ponderada em T2 com difusão (DWI) da ressonância magnética necessita validação. Objetivo: Investigar o prognóstico de pacientes com AVCl que recebem tratamento endovascular (EVT) em até 6 horas e de 6-24 horas usando tomografia computadorizada sem contraste (NCCT) e DWI. Métodos: Duzentos e nove pacientes com AVCl de circulação anterior submetidos a EVT foram divididos em $\leq 6$ horas e 6-24 horas. Pacientes com sintomas até 6 horas foram tratados se NIHSS $\geq 7$ e ASPECTS $\geq 5$; aqueles com AVCl ao despertar (WUS) ou com sintomas entre 6-24 horas da última vez em que foram vistos bem (WUS/AVC de fase tardia, LPS) foram tratados se NIHSS $\geq 7$ e ASPECTS $\geq 5$. Resultados: As porcentagens de pacientes submetidos a implante de stent intracraniano e angioplastia intracraniana sem stent diferiram entre os dois grupos ( $p<0,001)$. As taxas de recanalização 0, 1, 2a e 2b não diferiram entre 6 horas e $6-24$ horas ( $p>0,05)$. A taxa de recanalização de grau 3 no grupo 6 horas foi menor do que $6-24$ horas ( $p=0,043$ ). Pontuação na Escala Rankin (3 meses) não foi diferente ( $p=0,629)$. Conclusões: EVT é um tratamento seguro e eficaz para pacientes com WUS e LPS selecionados por meio de imagens baseadas em NCCT e DWI.

Palavras-chave: Tratamento Endovascular;Tomografia Computadorizada sem Contraste; Imagem de Difusão por Ressonância Magnética; Acidente Vascular Cerebral.

\footnotetext{
'Department of Neurosurgery, Tianjin Huanhu Hospital, Tianjin, China.

${ }^{2}$ Tianjin University, Tianjin, China.

${ }^{3}$ Tianjin Key Laboratory of Cerebrovascular and Neurodegenerative Diseases, Tianjin, China.

WM (10 https://orcid.org/0000-0001-5355-1787

Correspondence:Wei Ming; Email: drweiming@yandex.com.

Conflict of interest: There is no conflict of interest to declare.

Authors' contributions: WM, WS: devised the study design; RH, ML: were in charge of imaging data collection and processing; YL, WM: drafted the manuscript. All authors approved the final version of the manuscript.

Support: Key Science and Technology Supporting Project of Tianjin Key Research and Development Plan (19YFZCSY00260).

Received on July 8, 2020; Received in its final form on January 5, 2021; Accepted on January 9, 2021.
} 


\section{INTRODUCTION}

Recently, the benefit of selecting patients for endovascular treatment (EVT) beyond the 6-hour (h) time window using a tissue-based approach was demonstrated in two randomized trials ${ }^{1,2}$. The optimal imaging protocol for selecting patients is under debate, and it is still unknown whether a simpler and faster protocol might adequately select patients with wake-up stroke (WUS) and late-presenting stroke (LPS) for EVT.

Recent randomized controlled trials (RCTs) have provided Class I evidence for the efficacy of mechanical thrombectomy in acute ischemic stroke patients with large-vessel occlusion $(\mathrm{LVO})^{3}$. Endovascular thrombectomy has been widely accepted as the standard procedure for acute stroke patients with LVO within the $6 \mathrm{~h}$ time window ${ }^{1-3}$. Since publication of the Dawn and DEFUSE 3 trials $^{4,5}$, the time window for thrombectomy has been extended to 6-24 $\mathrm{h}^{6}$. However, patient selection relies on complex CT or MRI perfusion evaluation that was described in two clinical trials. With the success of nearly a dozen prospective clinical trials demonstrating the efficacy of mechanical thrombectomy, the focus now is on optimizing the decision to proceed to thrombectomy for the benefit of the individual patient ${ }^{7.8}$. The major advantage of MRI over CT is its capability to detect and precisely estimate the volume of the infarct core $^{9}$. This precision leads to better individual patient selection. Precision in measuring the core also makes its other advantage possible: elimination of the need to attempt to measure the "penumbra" with imaging. Through using simple method to screen patients, more patients can be benefited, including those with wake-up stroke and unknown onset of ischemic events, especially in developing countries where multiple imaging is unavailable. A simpler and faster protocol based on diffusion-weighted imaging (DWI) may adequately select patients with wake-up stroke (WUS) and late-presenting stroke (LPS) for $\mathrm{EVT}^{10}$.

The "DWI or CT Perfusion Assessment with Clinical Mismatch in the Triage of Wake-up and Late-Presenting Strokes Undergoing Neurointervention with Trevo" (DAWN) study confirmed that patients with acute ischemic stroke with a mismatch between the severity of the clinical deficit and the infarct volume who undergo thrombectomy within the 6-24 h time window have similar efficacy and safety profiles compared with those treated within $6 \mathrm{~h}$ of symptom onset ${ }^{6}$. However, whether T2 DWI-MRI is feasible remains to be validated.

To resolve this issue, the present study was designed to investigate the surgical outcomes and clinical prognosis of stroke patients who underwent EVT interventions within $6 \mathrm{~h}$ or in the 6-24 $\mathrm{h}$ time window after the onset of relevant symptoms based upon using both non-contrasted computed tomography (NCCT) and DWI.

\section{METHODS}

\section{Patient grouping}

All cases of patients coming to Tianjin Huanhu Hospital with a late-presenting or wake-up stroke, consisting of an anterior-circulation ischemic stroke, which was treated using an endovascular approach at this hospital between January and November 2018, were retrospectively retrieved from our prospectively maintained stroke database. Wake-up stroke (WUS) was defined as a stroke occurring during sleep in patients who were neurologically intact when they went to sleep, such that they presented symptoms of stroke in the following morning.

\section{Patient selection}

The inclusion criteria were that the patients needed to present with acute ischemic stroke within a $24 \mathrm{~h}$ time window from symptom onset, with the following characteristics: anterior circulation acute ischemic stroke; DWI-ASPECTS score $\geq$ 5 ; severe clinical deficits following physician evaluation, with NIHSS score $\geq 7$; large-vessel occlusion (M1, M1-M2 junction and carotid terminus); and premorbid modified Rankin Scale (mRS) score of $\leq 2$.

The exclusion criteria consisted of the following situations: concurrent myocardial infarction or severe infection (endocarditis or sepsis); uncontrollable hypertension, defined as systolic blood pressure $>185 \mathrm{mmHg}$ or diastolic pressure > $110 \mathrm{mmHg}$; life expectancy of < $90 \mathrm{~d}$ before stroke onset; pregnancy or lactation; known severe allergy to radiographic contrast medium; improvement of NIHSS score $>4$ in less than $1 \mathrm{~h}$; and wide mismatch between mean transit time (MTT) and cerebral blood volume (CBV) imaging. The study procedures were approved by the ethics committee of our hospital. Written informed consents were obtained from all patients enrolled in this study.

\section{Decision-making and imaging protocol}

The initial NIHSS and Glasgow Coma Scale scores were assessed by a neurologist. Our stroke triage protocol consists of non-contrast brain computed tomography (CT) followed by magnetic resonance angiography (MRA) and MRI. The MRI protocol consists of diffusion-weighted imaging, FLAIR, T2* and MRA. Patients were considered to be candidates for endovascular therapy if they had a relatively small infarct core on MRI (ASPECTS score $\geq 6$ ), anterior-circulation large vessel occlusion (internal carotid artery [ICA] or M1 or M2 segment middle cerebral artery [MCA] occlusion), and National Institutes of Health Stroke Scale (NIHSS) score of at least 6. Mechanical thrombectomy was performed by two physicians. Balloon-guide catheters with flow reversal and distal intracranial catheter were routinely used in our patients. The primary outcome in this study was the 3-month mRS score. 


\section{RESULTS}

\section{Baseline data}

Among 102 patients diagnosed with acute ischemic stroke, 40 cases were treated within the $6 \mathrm{~h}$ time window and 62 received treatment within the $6-24 \mathrm{~h}$ time window. In the $6 \mathrm{~h}$ time window group, the mean age of these 40 patients was $68.2 \pm 12.6$ years, while it was $70.2 \pm 11.2$ years in the $6-24 \mathrm{~h}$ time window group $(\mathrm{P}=0.73)$. The male-to-female ratio did not significantly differ between two groups $(\mathrm{P}=0.79)$. The proportions of atrial fibrillation and hypertension in the $6 \mathrm{~h}$ time window group were $35 \%$ and $80 \%$, which did not significantly differ from $32 \%$ and $83 \%$ in the other group (both P > 0.05). No statistically significant difference in the NIHSS and ASPECTS scores was observed between the two groups (both $\mathrm{P}>0.05$ ). The details of the site of occlusion are also illustrated in Table 1.

\section{Surgical approach and revascularization treatment}

Regarding the surgical pattern, the proportions of the patients who received intravenous tissue-type plasminogen activator (tPA), balloon-guide catheter, stent retriever and direct aspiration in the $6 \mathrm{~h}$ group were calculated as $5.8 \%, 18.9 \%$, $98.9 \%$ and $16.7 \%$. These did not significantly differ from $2.5 \%$, $17.7 \%, 92.8 \%$ and $17.6 \%$ in the $6-24 \mathrm{~h}$ group (all $\mathrm{p}>0.05$ ). The percentages of the patients treated with intracranial stenting and intracranial ballooning without stenting differed significantly between the two groups $(2.1 \%$ vs $13.1 \%, \mathrm{p}<0.001 ; 0.5 \%$ vs $17.1 \%, \mathrm{p}<0.001)$. Grades $0,1,2 \mathrm{a}$ and $2 \mathrm{~b}$ recanalization rates in the $6 \mathrm{~h}$ group were $2.0 \%, 1.0 \%, 2.0 \%$ and $49.6 \%$, and these did not significantly differ from the rates of $1.0 \%, 1.0 \%, 2.1 \%$ and $42.4 \%$ in the $6-24 \mathrm{~h}$ group (all $p>0.05$ ). The Grade 3 recanalization rate in the $6 \mathrm{~h}$ group was $29.9 \%$, which was significantly lower than the rate of $34.3 \%$ in the $6-24 \mathrm{~h}$ group $(\mathrm{p}=0.043)$. In addition, the successful reperfusion rate in the $6 \mathrm{~h}$ group was $95.0 \%$, which did not significantly differ from the rate of $94.8 \%$ in the other group ( $\mathrm{p}=0.537)$, as illustrated in Table 2 .

\section{Postoperative complications and clinical prognosis}

In terms of postoperative complications, the incidence rates of no hemorrhage, parenchymal hemorrhage, symptomatic hemorrhage and severe hemorrhage in the $6 \mathrm{~h}$ group were calculated as $84.6 \%, 1.8 \%, 2.8 \%$ and $2.8 \%$, which did not significantly differ from $82.7 \%, 1.1 \%, 1.9 \%$ and $1.9 \%$ in the $6-24$ $h$ group (all $p>0.05$ ). In the $6 \mathrm{~h}$ group, the incidence rate of subarachnoid hemorrhage was $2.4 \%$, which was significantly higher than the rate of $2.1 \%$ in the 6-24 h group, whereas the risk of re-occlusion on angiography in the $6 \mathrm{~h}$ group was $0 \%$, significantly lower than the risk of $5.7 \%$ in the other group (both $\mathrm{p}<0.05$ ). The median 3-month mRS score in the 6 h group was 2 , which did not differ significantly from the score of 3 in the $6-24 \mathrm{~h}$ group $(\mathrm{p}=0.629)$. One patient in the $6 \mathrm{~h}$ group died and none in the other group $(\mathrm{p}=1.00)$. The proportion of patients presenting with good outcomes ( $\mathrm{mRS} \leq 2)$ at 3 months in the $6 \mathrm{~h}$ group was calculated as $72.9 \%$, which did not differ significantly from the proportion of $83.3 \%$ in the $6-24 \mathrm{~h}$ group $(\mathrm{p}=$ 0.063), as demonstrated in Table 3.

Table 1. Baseline data on 102 enrolled patients.

\begin{tabular}{|c|c|c|c|}
\hline Variable & $6 \mathrm{~h}$ group $(n=40)$ & $6-24 h$ group $(n=62)$ & $\mathbf{P}$ \\
\hline Age, years (mean \pm SD) & $68.2 \pm 12.6$ & $70.2 \pm 11.2$ & 0.73 \\
\hline Female (\%) & $45(18 / 40)$ & $37(23 / 62)$ & 0.79 \\
\hline Atrial fibrillation (\%) & $35(17 / 40)$ & $32(20 / 62)$ & 0.764 \\
\hline Hypertension (\%) & $80(32 / 40)$ & $83(52 / 62)$ & 0.68 \\
\hline Smoking (\%) & $33(13 / 40)$ & $35(22 / 62)$ & 0.47 \\
\hline Hyperlipidemia (\%) & $20(10 / 40)$ & $24(15 / 62)$ & 0.54 \\
\hline Diabetes (\%) & $22(9 / 40)$ & $19(12 / 62)$ & 0.78 \\
\hline History of ischemic stroke (\%) & $8(3 / 40)$ & $8(5 / 62)$ & 0.65 \\
\hline Large artery atherosclerosis & $57(23 / 40)$ & $53(33 / 62)$ & 0.78 \\
\hline Cardio-aortic embolism & $20(8 / 40)$ & $32(20 / 62)$ & 0.66 \\
\hline Other causes & $2(1 / 40)$ & $5(3 / 62)$ & 0.48 \\
\hline Undetermined causes & $20(8 / 40)$ & $10(6 / 62)$ & 0.55 \\
\hline NIHSS score (mean \pm SD) & $16.3 \pm 6.6$ & $13.6 \pm 5.2$ & 0.86 \\
\hline ASPECTS score (mean \pm SD) & $7.6 \pm 1.6$ & $8.8 \pm 1.8$ & 0.78 \\
\hline \multicolumn{4}{|l|}{ Occlusion site } \\
\hline M1 & $28(70.0 \%)$ & $45(72.6 \%)$ & \\
\hline M2 & $2(5.0 \%)$ & $6(9.7 \%)$ & \\
\hline Internal carotid artery & $10(25.0 \%)$ & $11(17.7 \%)$ & \\
\hline
\end{tabular}


Table 2. Comparison of surgical methods and revascularization between the two groups.

\begin{tabular}{|c|c|c|c|}
\hline Variable & $6 \mathrm{~h}$ group $(n=40)$ & $6-24 h$ group $(n=62)$ & $\mathbf{P}$ \\
\hline Intravenous tissue-type plasminogen activator (tPA) & $13(5.8)$ & $4(2.5)$ & 0.093 \\
\hline Balloon guide catheter usage & $19(18.9)$ & $17(17.7)$ & 0.213 \\
\hline Stent retriever usage & $38(98.9)$ & $59(92.8)$ & 0.221 \\
\hline Direct aspiration usage & $2(16.7)$ & $3(17.6)$ & 0.085 \\
\hline Intracranial stenting & $9(2.1)$ & $13(13.1)$ & $<0.001$ \\
\hline Intracranial ballooning without stenting & $2(0.5)$ & $17(17.1)$ & $<0.001$ \\
\hline Number of techniques & $1(1-2)$ & $2(2-3)$ & $<0.001$ \\
\hline Single pass recanalization & 28 & 46 & 0.085 \\
\hline Grade 0 & $0(2.0)$ & $0(1.0)$ & 0.778 \\
\hline Grade 1 & $0(1.0)$ & $0(1.0)$ & 1.00 \\
\hline Grade $2 a$ & $2(2.0)$ & $3(2.1)$ & 0.223 \\
\hline Grade $2 b$ & $18(49.6)$ & $22(42.4)$ & 0.655 \\
\hline Grade 3 & $20(29.9)$ & $37(34.3)$ & 0.043 \\
\hline Successful reperfusion (grades $2 \mathrm{~b}-3$ ) & $38(95.0)$ & $59(94.8)$ & 0.537 \\
\hline
\end{tabular}

Table 3. Comparison of surgical complications and clinical prognosis between the two groups.

\begin{tabular}{|c|c|c|c|}
\hline Variable & $6 \mathrm{~h}$ group $(n=40)$ & $6-24 h$ group $(n=62)$ & $\mathbf{P}$ \\
\hline No hemorrhage & $34(84.6)$ & $54(82.7)$ & 0.565 \\
\hline Parenchymal hemorrhage, n (\%) & $2(1.8)$ & $1(1.1)$ & 0.280 \\
\hline Subarachnoid hemorrhage, n (\%) & $2(2.4)$ & $2(2.1)$ & 0.033 \\
\hline Symptomatic hemorrhage, n (\%) & $1(2.8)$ & $1(1.9)$ & 0.876 \\
\hline Serious hemorrhagic complications & $1(2.8)$ & $1(1.9)$ & 0.280 \\
\hline Re-occlusion on repeat angiography & $0(0)$ & $2(5.7)$ & $<0.001$ \\
\hline Median 3-month modified Rankin Scale (mRS) score (interquartile range) & $2(1-4)$ & $3(1-4)$ & 0.629 \\
\hline Good outcomes at 3 months (mRS $\leq 2$ ) & $28(72.9)$ & 50 (83.3) & 0.063 \\
\hline Mortality, n (\%) & 1 & 0 & 1.00 \\
\hline
\end{tabular}

\section{Imaging outcome evaluation}

As illustrated in Figure 1, the FLAIR sequence showed the hyperintense vessel sign of slow flow syndrome in the left frontotemporal region before surgery, whereas slow flow syndrome was absent after surgery. As shown in Figure 2, preoperative digital subtraction angiography (DSA) displayed carotid artery occlusion and postoperative DSA revealed the incidence of complete recanalization.

\section{DISCUSSION}

The "DWI or CT Perfusion Assessment with Clinical Mismatch in the Triage of Wake-up and Late-Presenting Strokes Undergoing Neurointervention with Trevo" (DAWN) trial and the "Endovascular Therapy Following Imaging Evaluation for Ischemic Stroke" (DEFUSE 3) trial showed that patient selection based on perfusion imaging showing salvageable tissue led to better patient outcomes. This core infarct volume was automatically generated by the RAPID software (iSchemiaView, Redwood City, California, USA), either on MRI diffusion weighted imaging (DWI) $)^{10}$ or on perfusion $\mathrm{CT}^{11}$. The recent
American Heart Association guidelines recommend using the criteria from these trials for patient selection for thrombectomy beyond $6 \mathrm{~h}$ after last seen well ${ }^{12}$.

Nevertheless, RAPID or other approved third-party software is unavailable in most centers in developing countries. The prospective observational study by Leslie-Mazwi et al. and the prospective, randomized DAWN trial by Nogueira et al. have demonstrated that direct imaging of the "penumbra" is not necessary for successful selection of patients for thrombectomy ${ }^{13}$.

At present, penumbral imaging is beset by the fundamental conundrum that there is no generally accepted definition for this imaging measurement. This lack of definition has led to adoption of measurements of altered contrast delivery times (Tmax) or contrast transit times (MTT), and use of DWI/Tmax or DWI/MTT mismatch for patient selection for thrombectomy. In the presence of a LVO, both oligemic and normally perfused tissue may exist beyond the infarct core. For example, a patient with chronic occlusion of a proximal ICA may have fully compensated normal arterial blood flow but would meet the criterion of a large "mismatch." As specifically addressed in the DAWN trial, a clinical "penumbra," i.e., the presence of a neurological deficit that is not completely explained by the 

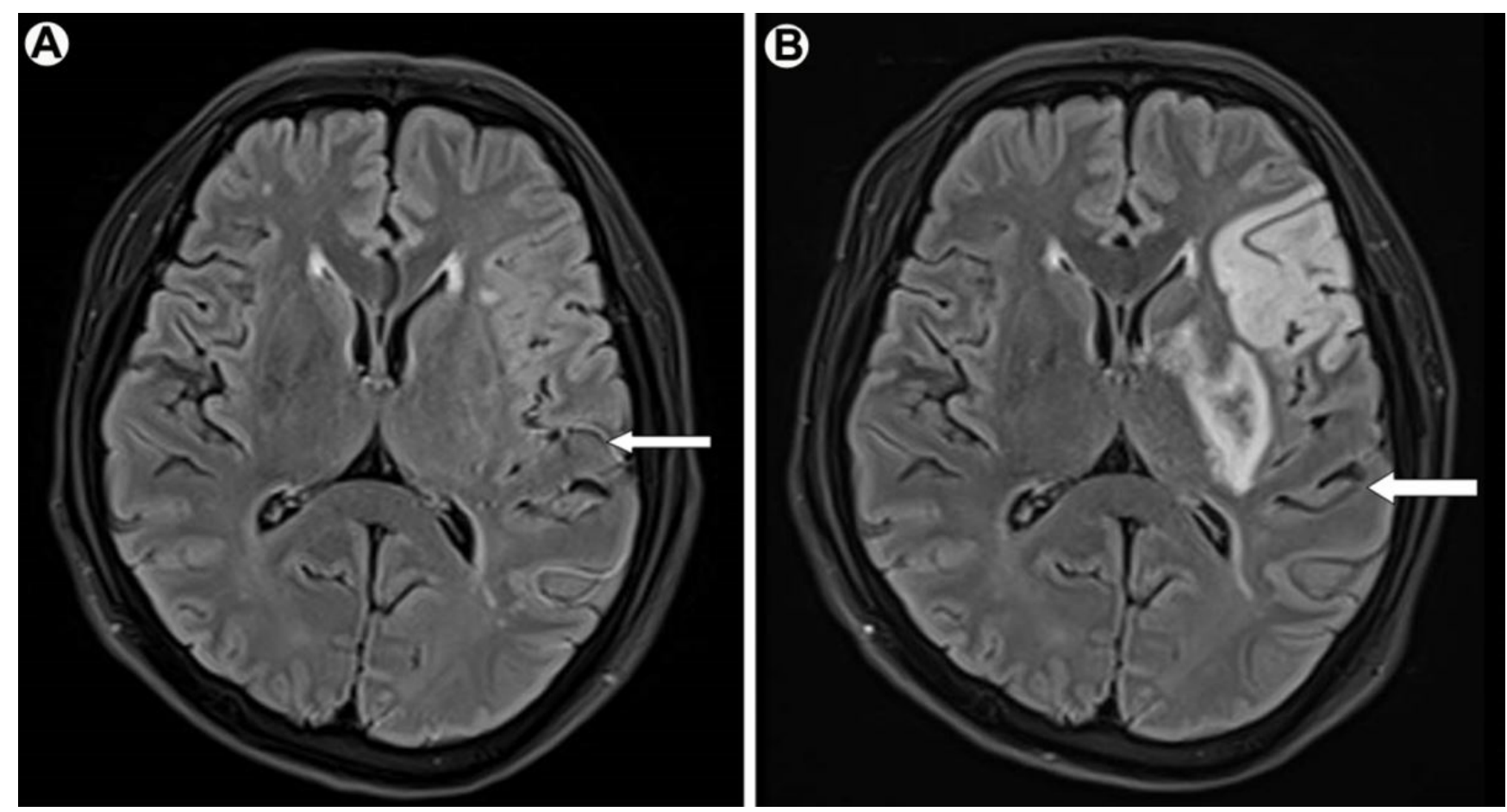

Figure 1. FLAIR sequence showing slow flow syndrome in the left frontotemporal region (A); whereas in (B), slow flow syndrome is absent.

infarct core visualized through DWI, is sufficient for proceeding to thrombectomy when there is a small core.

Perfusion imaging using MRI may be useful for assessing patients with ischemic stroke that is not caused by a LVO. Patients may present with an acute stroke syndrome due to occlusion of a small branch vessel that is not visualized through MRA or CT angiography (CTA). In this circumstance, dynamic contrast-enhanced perfusion imaging or arterial spin labeling may reveal a small volume of abnormal perfusion caused by the small-branch occlusion. These lesions are not amenable to mechanical thrombectomy.

Several studies have reported using ASPECTS scores instead of CT perfusion to select patients with wake-up stroke for thrombectomy, because there is lack of standardization and validation in acquisition and postprocessing of $\mathrm{CT}$ perfusion protocols. In one study, every patient was shown to experience a reduction in NIHSS score during hospitalization ${ }^{14}$.

Santos et al. ${ }^{15}$ used non-contrast computed tomography (NCCT) and CTA as the main imaging methods for evaluating the extent of salvageable brain tissue versus infarct core. Their study showed that there was no difference in symptomatic intracranial hemorrhage, peri-procedural complications or mortality between the groups. Three-month functional independence was similar in both groups $(65.1 \%$ in WUS/LPS vs $57.0 \%$ in $\leq 6 \mathrm{~h}$ ), and no differences were found after adjustment for confounders. This result was similar to the findings of our study, although the proportion with a good clinical outcome was less compared than in the present investigation. The discrepancy between previous studies and ours is reasonable, given that DWI was used to exclude patients with large infarct cores, which is a more reliable method than NCCT ASPECTS scores.

In addition, MRI is unparalleled for detecting the infarct core. MRI diffusion-weighted imaging (DWI) allows detection of acute ischemia as early as 30 minutes after the onset, with high sensitivity and specificity $(>90 \%)^{16}$. The final infarct volume, which is an independent predictor of the outcome, was dependent on the ischemic core and hypoperfusion volumes $^{17}$. Stroke volume can be a clinically relevant prognostic variable for counseling patients and their families regarding outcomes ${ }^{18}$. A previous study ${ }^{19}$ showed that it was more effective to exclude patients with large core infarctions, with the exception that MRI was more effective at reducing the rate of ineffective recanalization. Moreover, Longo et al..$^{20}$ used National Institute of Health Stroke Scale (NIHSS) score on admission $\geq 8$ and MRI-ASPECTS score $\geq 5$ as the selection criteria for patients to undergo mechanical thrombectomy. A favorable outcome (mRS 0-2) was found in $52.9 \%$ of the patients at the 3-month follow-up.

In the present study, patients with WUS were selected according to strict criteria and subsequently prepared for thrombectomy using the DWI core infarction findings. The postoperative outcomes suggested that the procedure was safe and efficacious, without incidence of spontaneous intracerebral hemorrhage or perioperative mortality. Regarding postoperative complications, only one patient presented with symptomatic intra-cerebral hemorrhage. A trend towards larger reduction in the NIHSS score in patients with Grade 3 recanalization, compared with those with Grade 2B recanalization, was observed. 

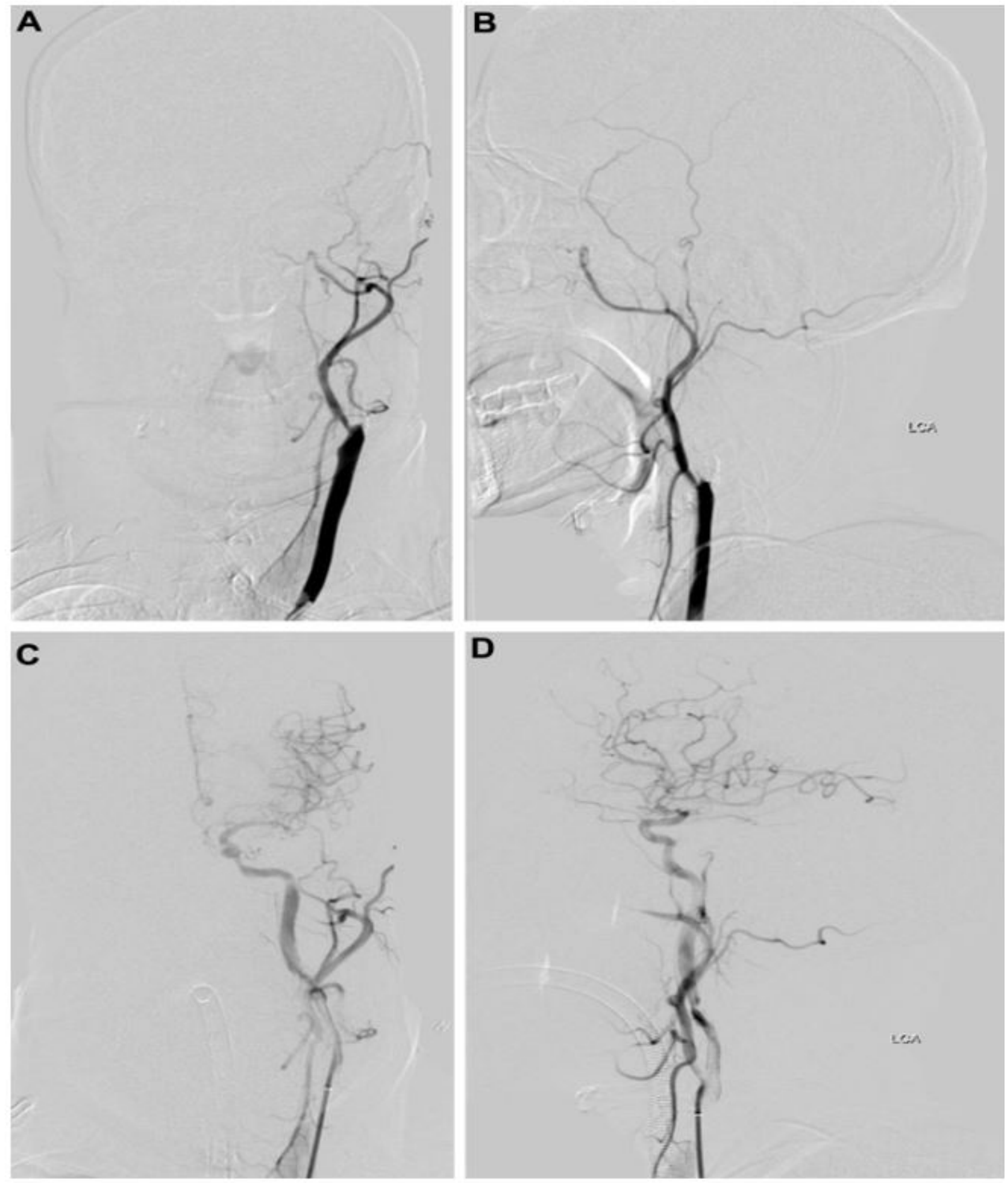

Figure 2. Preoperative digital subtraction angiography (DSA) showing carotid artery occlusion (A); postoperative DSA showing complete recanalization (B).

This underscored the need for high-quality recanalization in LVO patients, in clinical practice.

The main limitation of this study is the retrospective analysis. Pre-thrombectomy MRI screening of patients requires further in-depth clinical trial for verification. Preoperative selection for thrombectomy using MRI sequences, among patients beyond the time window, is safe and reliable, and this can achieve a good outcomes and reduce the incidence of surgical complications. 
1. Menon BK, Sajobi TT, Zhang Y, Rempel JL, Shuaib A, Thornton J, et al. Analysis of workflow and time to treatment on thrombectomy outcome in the ESCAPE randomized controlled trial. Circulation. 2016 Jun 7;133(23):2279-86. https://doi.org/10.1161/ CIRCULATIONAHA.115.019983

2. Desai SM, Rocha M, Molyneaux BJ, Starr M, Kenmuir CL, Gross BA, et al. Thrombectomy 6-24 hours after stroke in trial ineligible patients. J Neurointerv Surg. 2018 Nov;10(11):1033-7. https://doi.org/10.1136/ neurintsurg-2018-013915

3. Berkhemer OA, Fransen PSS, Beumer D, van den Berg LA, Lingsma HF, Yoo AJ, et al. A randomized trial of intraarterial treatment for acute ischemic stroke. N Engl J Med. 2015 Jan 1;372(1):11-20. https://doi. org/10.1056/NEJMoa1411587

4. Nogueira RG, Jadhav AP, Haussen DC, Bonafe A, Budzik RF, Bhuva $P$, et al. Thrombectomy 6 to 24 hours after stroke with a mismatch between deficit and infarct. N Engl J Med. 2018 Jan 4;378(1):11-21. https://doi.org/10.1056/NEJMoa1706442

5. Albers GW, Marks MP, Kemp S, Christensen S, Tsai JP, OrtegaGutierrez S, et al. Thrombectomy for stroke at 6 to 16 hours with selection by perfusion imaging. N Engl J Med. 2018 Feb 22;378(8):708-18. https://doi.org/10.1056/NEJMoa1713973

6. Ducroux C, Khoury N, Lecler A, Blanc R, Chetrit A, Redjem H, et al. Application of the DAWN clinical imaging mismatch and DEFUSE 3 selection criteria: benefit seems similar but restrictive volume cut-offs might omit potential responders. Eur J Neurol. 2018 Aug;25(8):1093-9. https://doi.org/10.1111/ene.13660

7. Bracard S, Ducrocq X, Mas JL, Soundant M, Oppenheim C, Moulin T, et al. Mechanical thrombectomy after intravenous alteplase versus alteplase alone after stroke (THRACE): a randomised controlled trial. Lancet Neurol. 2016 Oct 1;15(11):1138-47. https://doi.org/10.1016/ S1474-4422(16)30177-6

8. Desai SM, Haussen DC, Aghaebrahim A, Al-Bayati AR, Santos R, Nogueira RG, et al. Thrombectomy 24 hours after stroke: beyond DAWN. J Neurointerv Surg. 2018 Nov;10(11):1039-42. https://doi. org/10.1136/neurintsurg-2018-013923

9. Schröder J, Thomalla G. A critical review of Alberta stroke program early CT score for evaluation of acute stroke imaging. Front Neurol. 2017 Jan 12;7:245. https://doi.org/10.3389/fneur.2016.00245

10. Wolman DN, Iv M, Wintermark M, Zaharchuk G, Marks MP, Do HM, et al. Can diffusion- and perfusion-weighted imaging alone accurately triage anterior circulation acute ischemic stroke patients to endovascular therapy? J Neurointerv Surg. 2018 Dec;10(12):1132-6. https://doi.org/10.1136/neurintsurg-2018-013784

11. González RG, Copen WA, Schaefer PW, Lev MH, Pomerantz SR,
Rapalino O, et al. The Massachusetts General Hospital acute stroke imaging algorithm: an experience and evidence based approach. J Neurointerv Surg. 2013 Apr 8;5(1 Suppl 1):i7-12. https://doi. org/10.1136/neurintsurg-2013-010715

12. Powers WJ, Rabinstein AA, Ackerson T, Adeoye OM, Bambakidis NC, Becker K, et al. 2018 guidelines for the early management of patients with acute ischemic stroke: a guideline for healthcare professionals from the American Heart Association/American Stroke Association. Stroke. 2018 Mar;49:e46-110. https://doi.org/10.1161/ STR.00000000000000158

13. Leslie-Mazwi TM, Hirsch JA, Falcone GJ, Schaefer PW, Lev MH, Rabinov JD, et al. Endovascular stroke treatment outcomes after patient selection based on magnetic resonance imaging and clinical criteria. JAMA Neurol. 2016 Jan;73(1):43-9. https://doi.org/10.1001/ jamaneurol.2015.3000

14. Konstas AA, Minaeian A, Ross IB. Mechanical thrombectomy in wake-up strokes: a case series using Alberta Stroke Program Early CT Score (ASPECTS) for patient selection. J Stroke Cerebrovasc Dis. 2017 Jul 1;26(7):P1609-14. https://doi.org/10.1016/j. jstrokecerebrovasdis.2017.02.024

15. Santos T, Carvalho A, Cunha AA, Rodrigues M, Gregório T, Paredes $\mathrm{L}$, et al. NCCT and CTA-based imaging protocol for endovascular treatment selection in late presenting or wake-up strokes.J Neurointerv Surg. 2019 Feb;11(2):200-3. https://doi.org/10.1136/ neurintsurg-2018-014051

16. Schaefer PW, Grant PE, Gonzalez RG. Diffusion-weighted MR imaging of the brain. Radiology. 2000 Nov;217(2):331-45. https://doi. org/10.1148/radiology.217.2.ro0nv24331

17. Albers GW, Goyal M, Jahan R, Bonafe A, Diener H-C, Levy El, et al. Ischemic core and hypoperfusion volumes predict infarct size in SWIFT PRIME. Ann Neurol. 2016 Jan;79(1):76-89. https://doi. org/10.1002/ana.24543

18. Hand PJ, Wardlaw JM, Rivers CS, Armitage PA, Bastin ME, Lindley RI, et al. MR diffusion-weighted imaging and outcome prediction after ischemic stroke. Neurology. 2006 Apr 25;66(8):1159-63. https://doi. org/10.1212/01.wnl.0000202524.43850.81

19. Han M, Choi JW, Rim N-J, Kim SY, Suh H-I, Lee KS, et al. Cerebral infarct volume measurements to improve patient selection for endovascular treatment. Medicine (Baltimore). 2016 Aug;95(35):e4702. https://doi.org/10.1097/MD.0000000000004702

20. Longo M, Bernava G, Calamuneri A, Caragliano AA, Pitrone A, Papa $\mathrm{R}$, et al. MRI patient selection for endovascular thrombectomy in acute ischemic stroke: correlation between pretreatment diffusion weighted imaging and outcome scores. Radiol Med. 2018 Aug;123(8):609-17. https://doi.org/10.1007/s11547-018-0887-2 